\title{
PEMIKIRAN PASCA ISLAMISME DALAM KONTEKS GERAKAN ISLAM DI MALAYSIA
}

\author{
Wan Ahmad Fahmi Bin Wan Muda \\ Jabatan Usuluddin dan Falsafah, Fakulti Pengajian Islam, \\ Universiti Kebangsaan Malaysia, 43600, Bangi \\ *Corresponding author: Fami_0307@yahoo.com
}

\section{Article history}

Received: 2015-12-21
Received in revised form: 2016-04-17

\begin{abstract}
Post-Islamism is a new trend that emerged in the work of political Islam after the emergence of Islamism in line with the demands of the requirements democracy. Thus, most of the Islamic movements worldwide give different interpretations of the concept of the Islamic state, the issue of implementing Islamic law and cooperation between the non-Muslims. The development of this trend began to produce the Islamists who support opinionated approach to post-Islamism in political Islam, including among Islamic movements in the country. The objective of this study to analyze the elements of post-Islamism thought in the Islamic movement in Malaysia. This study is qualitative. The method of collecting data using document analysis of journals, articles, theses, books and works of scholars who talk about the development of post-Islamism and the Islamist movement worldwide. Meanwhile, data analysis using descriptive and historical approach through content analysis. The study concluded that not only Islamic movements in the Middle East and West Asia receive thinking Post-Islamism, but Islamic movements in Malaysia was also impressed with the development of post-Islamism.
\end{abstract}

Keywords: Post-Islamism, Islamic Movement, Democracy

\begin{abstract}
Abstrak
Pasca Islamisme merupakan trend baharu yang timbul dalam gerak kerja politik Islam. Kemunculan Pasca Islamisme selari dengan tuntutan memenuhi kehendak demokrasi. Justeru, kebanyakan gerakan Islam seluruh dunia mulai berbeza tafsiran terhadap konsep negara Islam, isu pelaksanaan undang-undang Islam dan kerjasama antara NonMuslim. Perkembangan trend ini melahirkan golongan Islamis yang mulai berpendirian menyokong pendekatan Pasca Islamisme dalam arena politik Islam termasuk dalam kalangan gerakan Islam di Malaysia. Objektif kajian ialah menganalisis unsur-unsur pemikiran Pasca Islamisme dalam gerakan Islam di Malaysia. Kajian ini merupakan kajian kualitatif. Kaedah pengumpulan data menggunakan metode analisis dokumen terhadap jurnal, artikel, tesis, buku, dan karya sarjana yang membicarakan tentang Pasca Islamisme dan perkembangan gerakan Islam seluruh dunia. Analisis data pula menggunakan metode deskriptif dan metode sejarah menerusi analisis kandungan. Dapatan kajian merumuskan bahawa bukan sahaja gerakan Islam di Timur Tengah dan Asia Barat menerima pemikiran Pasca Islamisme, tetapi gerakan-gerakan Islam di Malaysia juga turut terkesan dengan perkembangan Pasca Islamisme.
\end{abstract}

Kata Kunci: Pasca Islamisme; Gerakan Islam; Demokrasi 


\subsection{PENDAHULUAN}

Pasca Islamisme merupakan fahaman masa kini golongan Islamis tentang politik Islam. Trend ini timbul selepas Revolusi Iran 1979 apabila diperkenalkan oleh Asef Bayat profesor dalam bidang Sosiologi di Universiti Lllinois, Amerika Syarikat berikutan kegagalan corak Islamisme yang lebih menekankan kepada retorik negara Islam berbanding kepada nilai praktis (Bayat, 1996: 43-44). Kajian ini berdasarkan kepada kenyataan Asef Bayat dalam artikelnya, What Is Post Islamism 2005 yang menjelaskan kedatangan fasa baharu, iaitu Pasca Islamisme dalam kalangan gerakan Islam seluruh dunia.

"He (Asef Bayat) posits that Islamist movements in Muslim societies are undergoing a postIslamist turn characterized by rights instead of duties, plurality in place of singular authoritative voice, historicity rather than fixed scriptures and the future instead of the past." (Bayat, 2005: 5).

Kemunculan Pasca Islamisme menggesa kepada pengkajian yang lebih mendalam oleh sarjana Islam dan sarjana Barat seperti Husnul Amin dengan tesisnya From Islamism To Post - Islamism A Study of a New Intellectual Discourse on Islam and Modernity in Pakistan (2010), Ihsan Dagi dalam tulisannya Post-Islamism a la Turca (2013), Noah Feldman dalam tulisannya Failure of Egypt Democracy (2013) dan Noorhaidi Hasan dalam tulisannya Post-Islamist Politics in Indonesia 2013. Nilai dan ciri yang dibawa Pasca Islamisme seperti toleransi, partisipasi, dan inklusif telah mencorak gerak kerja gerakan Islam seluruh dunia. Sehubungan itu, timbul persoalan adakah gerakan Islam di Malaysia turut terkesan dengan perkembangan Pasca Islamisme? Justeru, kajian ini menganalisis pengaruh Pasca Islamisme dalam gerakan Islam di Malaysia.

\subsection{METODE KAJIAN}

Makalah ini menggunakan reka bentuk kajian kualitatif secara analisis kandungan. Data dikumpul melalui analisis dokumen yang merangkumi kesemua bentuk dokumen seperti buku, kajian ilmiah, jurnal, dan artikel. Bahan kajian utama yang dirujuk oleh pengkaji ialah tulisan tokoh-tokoh intelektual yang menulis tentang Pasca Islamisme. Namun, fokus rujukan pengkaji lebih meneliti kepada tulisan Asef Bayat dengan mengambil kira konteks Pasca Islamisme yang diperkenalkan melalui tulisannya. Antara tulisan utama Bayat yang dirujuk bagi mengumpulkan data ialah The Coming of Post Islamist (1996), What Is Post Islamismt (2005) dan Post-Islamism The Changing Faces of Political Islam (2013). Selain itu, pengkaji menggunakan metod sejarah dengan meneliti peristiwa dan sejarah di kebanyakan negara yang terkesan dengan Pasca Islamisme untuk disesuaikan dengan realiti di Malaysia. Data pula dianalisis menggunakan metode deskriptif melalui analisis kandungan. Dapatan kajian disusun berdasarkan kaedah tematik untuk mengenalpasti ciri-ciri Pasca Islamisme yang terdapat dalam pengamalan gerakan politik muslim dan gerakan Islam di Malaysia.

\subsection{SEJARAH PASCA ISLAMISME DAN PERKEMBANGANNYA DI SELURUH DUNIA}

Sebelum kemunculan wacana Pasca Islamisme, sarjana Barat menamakan perjuangan gerakan Islam sebagai Islamisme. Dalam kebanyakan keadaan, Islamisme dianggap satu fenomena kontemporari yang kompleks dan ideologi bagi suatu gerakan dan organisasi yang berhasrat membentuk pemerintahan. Mozaffari dalam artikelnya, What is Islamism? History and Definition of a Concept (2007) menyatakan bahawa "Islamism is a religious ideology with a holistic interpretation of Islam whose final aim is the conquest of the world by all means". Kenyataan ini bermaksud ideologi agama dengan tafsiran holistik terhadap Islam yang matlamat akhirnya ialah menakluki dunia dengan segala cara (Mozaffari, M, 2007: 21). 
Asef Bayat menganalisis Pasca Islamisme dengan katanya "I saw post-Islamism not only as a condition but also as a project, a conscious attempt to conceptualize and strategize the rationale and modalities of transcending Islamism in social, political, and intellectual domains" (Bayat, 2013: 8). Beliau menterjemahkan Pasca Islamisme sebagai bentuk strategi golongan Islamis bagi meneruskan survival perjuangan Islam dalam politik. Bagi Ihsan Dagi, "Post Islamism is not only about changing strategies for political struggle. Its is deeper and more fundamental: abandoning the idea and ideal that an Islamic state is both theoretically and politically possibly possible". Beliau menterjemah Pasca Islamisme dengan maksud perubahan strategi politik Islam dengan meninggalkan idea fundamental yang bersifat teori negara Islam kepada idea yang lebih realistik (Ihsan Dagi, 2013: 73).

Sementara itu Noah Feldman pula menjelaskan bahawa Pasca Islamisme sebagai fasa berbeza dengan sebelumnya (Islamisme) yang digunakan oleh Islamis dalam menanggapi dan memahami sesuatu isu. Dalam hal ini, beliau membuat perbandingan antara Parti Ennahda di Tunisia dan al-Ikhwan alMuslimun di Mesir. Kata Feldman "The contrasting personalities and styles of their leaders, however, have pushed Ennahda and the Brotherhood to behave differently when negotiating religion with secularists in their respective countries" (Feldman, 2013).

Kewujudan Pasca Islamisme masih lagi baru yang berkisar sekitar tahun 1980 selepas Revolusi Iran 1979. Wacana ini mulai membentuk kerangka pengamalan sekitar pertengahan tahun 1990. Pada awalnya, Pasca Islamisme hanya wujud dalam bentuk teori semata-mata dan bukannya dalam bentuk praktikal. Menurut Asef Bayat dalam artikelnya, The Making of Post-Islamist Iran (2013), pengamalan wacana Pasca Islamisme pertama kali berlaku di Tehran, Iran pada tahun 1992 (Asef Bayat, 2013: 39). Asef Bayat banyak menghasilkan tulisan, karya, dan artikel yang membicarakan tentang politik Islam dan perubahan perkembangan gerakan Islam. Pada tahun 1996, beliau menulis artikel yang berkaitan dengan kedatangan fasa baharu dalam kalangan gerakan Islam, iaitu The Coming of a Post-Islamist Society (1996)(Asef Bayat,1996: 43-52).

Pada tahun 2005, Bayat dalam artikelnya, What Is Post Islamism? (2005) mengulas dengan lebih mendalam trend Pasca Islamisme dengan menerangkan bahawa trend ini mulai berkembang di beberapa negara selain Iran seperti Tunisia, Mesir, dan Turki (Bayat, 2005:43-52). Kemunculan Pasca Islamisme terus dirancakkan dengan perkembangan fenomena Arab Spring yang berlaku di negara-negara Arab pada awal tahun 2010 yang menuntut hak rakyat seperti keadilan sosial, politik, dan ekonomi dikembalikan. Mohd Safar Hasim dalam artikelnya, Arab Spring atau Arab Nightmares menjelaskan bahawa antara hakikat dan persepsi kebangkitan Arab memberikan definisi fenomena Arab Spring diguna kepada definisi kebangkitan rakyat Arab untuk memberi maksud perubahan yang diharapkan berlaku berikutan kebangkitan (Mohd Safar, 2015: 94). Menurut Manfreda pula Arab Spring dikaitkan dengan kebangkitan rakyat yang menyuarakan hak mereka kepada kerajaan supaya dikembalikan semula (Manfreda, P, 2011).

Selepas Tunisia, kebangkitan rakyat juga berlaku di Mesir yang bermula pada 25 Januari 2011 dan berlangsung selama 18 hari yang akhirnya menggulingkan pemerintahan kerajaan Mesir (Haris, 2012). Fenomena Arab Spring terus menular di beberapa tempat di negara-negara Arab seperti di Libya, Yaman, dan Syria. Peristiwa Arab Spring merupakan fenomena yang telah mengubah struktur dunia Arab yang awalnya mengarah kepada penggulingan rejim pemerintah. Fenomona Arab Spring ini bagi masyarakat Arab membawa harapan baharu kepada rakyat di negara masing-masing. Fasa perubahan dalam politik dunia Arab selari dengan tuntutan demokrasi dan hak rakyat yang mulai hilang kepercayaan terhadap bentuk pemerintahan bentuk autokrasi. Peralihan paradigma politik Islam dengan perkembangan demokrasi dan sistem pilihan raya telah mendesak pendokong gerakan Islam berusaha untuk merealisasikan cita-cita tersebut dengan menukar corak gerak kerja berbanding dekad 80 an yang lebih bersifat retorik. Hal ini ditegaskan oleh Ihsan Dagi dengan kenyataannya:

"The regime changes in Arab world starting with Tunisia and followed up by Egypt, and the role performed by the Islamists in these countries, have now added new urgency to developing fresh approaches to the Muslim view on politics." (Ihsan Dagi, 2013: 72) 
Kebangkitan rakyat Arab menuntut demokrasi, kebebasan, dan keadilan sosial dikaitkan dengan trend Pasca Islamisme. Trend Pasca Islamisme ini menyatakan bahawa ideologi tidak lagi penting, kurang penekanan dan tiada sebarang penetapan terhadap pemakaian satu-satu ideologi dalam perjalanan gerakan Islam (Bayat, 2005: 5). Menurut Mohd Izani Mohd Zain dalam artikelnya, Islam dan Demokrasi: Impak dan Masa depan politik di Mesir menjelaskan bahawa wujud kekosongan ruang masa proses transisi pengisian kepada Demokrasi selepas kejatuhan pemerintahan dunia Arab. Hal ini menyebabkan pimpinan parti politik di negara Arab mulai memandang trend pemerintahan berhaluan Pasca Islamisme sebagai yang paling relevan kerana contoh kejayaan corak pengamalannya oleh beberapa negara seperti Iran dan Turki. Pengamalan corak pemerintahan sebelum ini lebih bersifat autokratik dan tidak memberi banyak manfaat kepada sistem ekonomi, sosial masyarakat dan pembangunan negara. Oleh yang demikian, proses pengisian kepada demokrasi memerlukan kepada pembaharuan yakni dengan memilih haluan yang berbeza daripada sebelum ini. Hal sedemikian disokong oleh tokoh pengkaji Barat seperti Oliver Roy yang menulis dalam bukunya The Failure of the Political Islam yang menegaskan tentang kegagalan corak pengamalan Islamisme dalam kalangan gerakan Islam seluruh dunia (Oliver Roy, 1996: x-xi).

Kajian yang telah dilakukan oleh Asef Bayat dalam tulisannya, Life as Politics: How Ordinary People Change The Middle East" (2010) mengulas bahawa sebelum kedatangan bentuk pemikiran baru, Islam di Timur Tengah dianggap sebagai kekal dan beku dalam tradisi sendiri. Bayat seterusnya berhujah bahawa rantau Arab telah gagal dalam memberi model contoh politik Islam terbaik sekaligus bakal mencetuskan fenomena kebangkitan rakyat di seluruh rantau tersebut. Trend Pasca Islamisme kemudiannya diangkat sebagai satu-satunya penyelesaian kepada masalah 'Arab Spring' yang menuntut kebanyakan masyarakat di Timur Tengah memilih haluan Pasca Islamisme dalam melaksanakan bentuk pemerintahan melalui penciptaan ruang sosial yang baharu dalam suasana budaya masyarakat dan ekonomi (Bayat, 2010: 241-243).

Kajian lepas turut membicarakan perkembangan Pasca Islamisme di Indonesia. Menurut Noorhaidi Hasan dalam artikelnya, Post-Islamist Politics in Indonesia 2013 membahaskan perubahan kerangka politik Islam selepas kepimpinan Presiden Suharto. Penerimaan awal idea Pasca Islamisme di Indonesia bermula dengan kebangkitan fahaman Muslim kelas pertengahan yang terlibat aktif dalam perbahasan mengenai matlamat politik Islam yang mendesak ke arah politik yang diasaskan kepada realiti dan praktis. Paradigma perubahan politik Islam turut dikesan dalam Parti Keadilan Sejahtera (PKS) yang di awal penubuhannya berprinsip Islamis dan kemudiannya menukar strategi ke arah pembahagian kuasa dalam proses demokrasi dan sistem pilihan raya Indonesia yang menghala ke arah lebih bersifat inklusif dan liberal dalam gerak kerja sebagai sebuah parti politik Islam (Noorhadi Hasan, 2013: 157-158).

Bagi Bayat, pengalaman Pasca Islamisme di Iran merupakan fasa penting dalam mempengaruhi gerakan Islam seluruh dunia terhadap trend ini (Bayat, 2013: 9). Idea dan nilai pemikiran ini mulai diamalkan dan diterima dalam kalangan gerakan Islam seluruh dunia seperti Turki, Tunisia, Mesir, Morocco, Sudan, dan Indonesia. Bahkan, Husnul Amin turut membahaskan dalam tesisnya From Islamism To Post-Islamism A Study Of A New Intellectual Discourse On Islam And Modernity In Pakistan (2010) bahawa Pakistan turut menerima pengaruh Pasca Islamisme (Amin, H, 2010: 1-3). Secara umumnya, kegagalan politik Islam ditambah dengan keperluan kepada gerakan Islam memenuhi tuntutan demokrasi dan pemerolehan kuasa pemerintahan melalui sistem pilihan raya menyebabkan trend Pasca Islamisme dilihat sebagai satu alternatif pilihan bagi gerakan-gerakan Islam di seluruh dunia bagi menyesuaikan diri dengan situasi global.

\subsection{PERKEMBANGAN PASCA ISLAMISME DI MALAYSIA}

Perkembangan Pasca Islamisme di seluruh dunia telah membuka ruang perbahasan dan tafsiran yang baharu dalam gerak kerja Islam. Kini, politik Muslim seluruh dunia termasuk di Malaysia berhadapan dengan fasa baharu yang kini berbeza dengan sebelumnya. Rajah 1.0 menunjukkan carta alir peralihan daripada trend Islamisme kepada Pasca Islamisme. Teori ini diperkenalkan oleh Asef Bayat dalam artikelnya, Islamism and Social Movement Teory (2005), tentang Social Movement Theory (Teori Gerakan Sosial) yang menjelaskan peralihan daripada fasa Islamisme kepada Pasca Islamisme dan kesan- 
kesan peralihan kepada sosio budaya masyarakat (Bayat, 2005: 891). Pengkaji berpandangan bahawa Teori Gerakan Sosial ini merupakan proses kritikan terhadap fasa Islamisme yang dilihat jumud bagi sesetengah golongan Islamis dalam menangani isu global sehingga berlaku proses tafsiran yang berbeza dalam beberapa isu terutamanya konsep negara Islam, pelaksanaan Undang-undang Islam dan kerjasama dengan bukan Islam.

Rajah 1.0: Peralihan Fasa Baharu dalam Gerakan Islam

\begin{tabular}{|c|c|c|}
\hline Islamisme & $\begin{array}{c}\text { Teori Gerakan } \\
\text { Sosial (Social } \\
\text { Movement Teory) }\end{array}$ & $\begin{array}{c}\text { Pasca } \\
\text { Islamisme }\end{array}$ \\
\hline
\end{tabular}

Secara umumnya, pengaruh Pasca Islamisme di Malaysia tidak sama sebagaimana di Timur Tengah, Barat, Asia Barat, dan di Asia Tenggara. Kewujudannya masih lagi baharu dan sedang berkembang membentuk hala tuju tersendiri. Justeru, terdapat beberapa perbezaan perkembangan Pasca Islamisme negara-negara lain dengan Malaysia. Justifikasi pengaruh perkembangan Pasca Islamisme di Malaysia dapat diorientasikan dalam 3 aspek. Pertama, walaupun telah terdapat kajian lepas tentang pengaruh Pasca Islamisme di seluruh dunia, namun kajian terhadap gerakan Islam di Malaysia masih baharu. Kedua, pembinaan dasar awal gerakan Islam di Malaysia dipacukan kepada wadah Islamisme berbanding kebanyakan gerakan Islam lain di dunia yang terasnya dibina dengan kerangka politik. Ketiga, realiti budaya masyarakat Malaysia juga menunjukkan bahawa Malaysia sangat berbeza dengan negara-negara lain di dunia dengan amalan agama yang kukuh. Maka, sudah tentulah penerimaan pengaruh Pasca Islamisme di Malaysia tidak akan sama berbanding negara-negara lain.

Faiz Mukmin telah membahaskan tentang perkembangan trend ini dalam artikelnya, Pemikiran Pasca Islamisme dalam PAS: Analisa terhadap Kesan Tahaluf Siyasi (2014). Beliau menegaskan bahawa PAS telah terkesan terhadap pemikiran Pasca Islamisme, iaitu apabila PAS mengadakan kerjasama dengan orang bukan Islam (Tahaluf Siyasi) khasnya DAP dan PKR di samping konsep menegakkan negara Islam dan cita-cita negara berkebajikan. Kesan Tahaluf Siyasi menyebabkan PAS terpaksa menerima hak-hak yang disepakati dalam Pakatan Rakyat dan berkompromi termasuk dalam soal prinsip agama Islam disebabkan suara minoriti PAS berbanding DAP dan PKR. Di samping itu, idea Pasca Islamisme yang menjadi pengamalan PAS turut memberi kesan kepada pengurangan undi orang Islam kepada PAS kerana kerjasama mereka dengan DAP (Faiz Mukmin, 2014: 667). Konsep tahaluf Siyasi bersesuian dengan idea Pasca Islamisme yang digambarkan sebagai satu strategi baharu dalam politik Islam untuk meraih kekuasaan. Hal ini juga turut ditegaskan oleh Ihsan Dagi sebagaimana berikut:

"Post Islamism also includes a political strategy that utilizes democracy within a new language that enables building coalitions with different political and social groups"(Ihsan Dagi, 2013: 72)

Berdasarkan kepada kajian Faiz Mukmin, gerakan politik Islam sebagaimana PAS telah terpalit dengan perkembangan idea Pasca Islamisme. Asef Bayat sendiri dalam tulisannya Post-Islamism at Large menyamakan prinsip Parti Keadilan Rakyat (PKR) di Malaysia dengan Parti Keadilan Sosial (PKS) di Indonesia melalui perubahan perkembangan doktrin oleh Parti Keadilan Rakyat (PKR) yang memfokuskan kepada terma keadilan, good governance, hak asasi manusia, dan mengiktiraf prinsip sekular dalam politik kenegaraan (Bayat, 2013:14-15). Justeru, sememangnya tidak dapat dinafikan bahawa Malaysia juga turut terkesan dengan trend pemikiran ini. Oleh yang demikian, pengkaji memberi justifikasi bahawa gerakan-gerakan Islam yang lain di Malaysia seperti ABIM, IKRAM, ISMA, HALUAN, dan JIM turut menerima pengaruh pemikiran Pasca Islamisme. Namun, kajian yang lebih mendalam perlu dijalankan terhadap gerakan Islam tersebut yang sifatnya bukan partisan yang sudah tentulah memberi implikasi daripada konteks yang berbeza berbanding PAS yang merupakan sebuah parti politik. 


\subsection{KESIMPULAN}

Dimensi baharu politik semasa menyaksikan tuntutan kepada keperluan demokrasi dalam sistem urus selia negara. Keperluan-keperluan semasa yang mementingkan kebaikan ekonomi, politik, dan sosial yang diasaskan kepada realiti dan praktis dilihat satu keutamaan berbanding perjuangan gerakan Islam dekad 80 an yang didasarkan kepada ucapan retorik semata-mata. Perubahan landskap politik dunia ini turut diiringi oleh trend Pasca Islamisme yang berkembang dalam kerangka pemikiran golongan Islamis khasnya selepas Revolusi Iran 1979 yang melihat bahawa Pasca Islamisme adalah satu solusi kepada gerakan Islam dalam menyelesaikan isu-isu global. Gerakan Islam yang dipalit krisis identiti dan ideologi dalam menyesuaikan diri dengan suasana global melihat trend pemikiran ini paling bersesuaian dalam konteks bahasa dunia. Justeru, kajian-kajian yang lebih terperinci dan berfokus khusus kepada satu persatu gerakan Islam di Malaysia adalah penting untuk dijalankan supaya hasil kajian dapat memberi orientasi pemikiran bagi gerakan Islam menyaring unsur-unsur Barat. Meskipun begitu, memang tidak dapat dinafikan bahawa trend Pasca Islamisme ini mengerakkan pelbagai hal yang positif kepada gerakan Islam. Namun, kebaikan dan nilai yang positif bukanlah tiket untuk gerakan Islam menghalalkan soalsoal liberalisme dalam dasar perjuangan.

\section{Rujukan}

Amin, H. (2010). From Islamism To Post - Islamism A Study of a New Intellectual Discourse on Islam and Modernity in Pakistan: The Netherlands. International Institute of Social Studies The Hague.

Bayat, Asef. (1996). The Coming of Post-Islamist Society. Journal Critical Middle East Studies. 43-52.

Bayat, Asef. (2005). What Is Post-Islamism. ISIM Review 16: 5.

Bayat, Asef. (2010). Life as Politics: How Ordinary People Change the Middle East. Stanford: Stanford University Press.

Bayat, Asef. (2013). The Making of Post-Islamist Iran. In A. Bayat. Post-Islamism The Changing Faces of Political Islam, New York: Oxford University Press. pp. 35-70.

Bayat, Asef. (2013). Post-Islamis at Large. In A. Bayat, Post-Islamism The Changing Faces of Political Islam, pp. 3-32. New York: Oxford University Press.

Faiz Mukmin. (2014). Pasca Islamisme dalam PAS: Analisa terhadap Kesan Tahaluf Siyasi. Bangi, Selangor: Prosiding Kolokium Antarabangsa Siswazah Pengajian Islam (KASPI).

Haris Zalkapli. (2012). Kebangkitan Gerakan Islam dalam Fenomena Arab Spring. Kuala Lumpur: Jundi Resources. http://www.academia.edu/3812208/Paper_Fenomena_Arab_Spring (20 Jun 2015).

Ihsan Dagi. (2013). Post-Islamism a la Turca. In A. Bayat, Post Islamism The Changing Faces of Political Islam (pp. 71-108). New York: Oxford University Press.

Manfreda, P. (2011). Definition of the Arab Spring. Human Rights, Civil Liberties and Democracy Movements. http://middleeast.about.com/od/humanrightsdemocracy/Definition-Of-The-Arab-Spring. html ( 20 Jun 2015).

Middlebrook. (2011). Re-Thinking The Arab Spring \& RoadMap for G20/UN Support. USA: Geopolicity Offices.

Mohd Safar Hasim. (2015). Arab Spring atau Arab Nightmares: Antara Hakikat dan Persepsi Kebangkitan Arab. Arab Spring Faktor dan Impak. Bangi: Universiti Kebangsaan Malaysia. Pp. 93-100.

Mozaffari, M. (2007). What is Islamism? History and Definition of a Concept. Totalitarian Movements and Political Religions, 8(1), 17-33.

Noah Feldman.(2013). www.bloombergview.com: http://www.bloombergview.com/articles/2013-07-05/don-tblame-islam-for-the-failure-of-egypt-s-democracy (21 Jun 2015].

Roy Oliver. (1996). The Failure Of The Political Islam. United Stated: Harvad University Press. 